\title{
RELAÇÕES DE GÊNERO NO TRABALHO DOMÉSTICO: um estudo a partir da realidade das trabalhadoras do Instituto Federal de Santa Catarina
}

\author{
RELACIONES DE GÉNERO EM EL TRABAJO DOMÉSTICO: un \\ estudio a partir de la realidad de las trabajadoras del Instituto Federal \\ de Santa Catarina
}

Conceição Garcia Martins[1]

Nanci Stancki da Luz[2]

Marília Gomes de Carvalho[3]

\section{RESUMO}

Este artigo apresenta resultados de uma pesquisa quantitativa - dados coletados por meio de um questionário eletrônico - realizada com cento e vinte mulheres trabalhadoras do Instituto Federal de Santa Catarina e cujo objetivo era analisar a divisão do trabalho doméstico em residências de famílias de mulheres trabalhadoras. A investigação mostrou que, embora as mulheres pesquisadas tenham ocupado lugar no mercado de trabalho e mesmo, quando são as que contribuem com a maior parcela da renda familiar, no ambiente doméstico permanecem assumindo a maior parte das tarefas domésticas. Os homens - companheiros, esposos, filhos ou outros familiares - continuam sendo vistos como colaboradores na esfera privada, revelando que as alterações na distribuição do trabalho doméstico ainda é um desafio na conquista da equidade de gênero.

Palavras-chave: trabalho doméstico; divisão sexual do trabalho; gênero.

\section{RESUMEN}

Este artículo presenta los resultados de un estudio cuantitativo - los datos recogidos a través de un cuestionario electrónico - llevado a cabo con ciento veinte mujeres trabajadoras del Instituto Federal de Santa Catarina, cuyo objetivo fue analizar la división del trabajo doméstico en hogares de las familias de las mujeres trabajadoras. La investigación ha demostrado que, aunque las mujeres encuestadas han tenido lugar en el mercado de trabajo e incluso cuando son ellas las que aportan la mayor parte de los ingresos familiares, en el hogar ellas permanecen asumiendo la mayoría de las tareas domésticas. Los hombres amigos, cónyuges, hijos u otros familiares - aún son vistos como colaboradores en la esfera privada, revelando que los cambios en la distribución del trabajo doméstico siguen siendo un desafío en el logro de la equidad de género.

Palabras-clave: trabajo doméstico; división sexual del trabajo; género. 


\section{INTRODUÇÃO}

Numa tradicional divisão sexual do trabalho, às mulheres coube a responsabilidade pela manutenção da casa e do cuidado com os membros da família e aos homens, o papel de provedor. O movimento feminista, dentre os diversos temas abordados, questionou essa divisão que além de associar o espaço privado ao feminino e a esfera pública ao masculino, também atribuía maior valor e visibilidade às atividades desenvolvidas pelos homens.

A crítica às formas de distribuição do trabalho contribuiu para que tarefas desenvolvidas majoritariamente por mulheres - serviços domésticos e cuidado com familiares - fossem visibilizadas. A luta pelo direito à igualdade no mundo do trabalho possibilitou alterar concepções sobre trabalho masculino e feminino, contribuiu para a redução da segregação do trabalho das mulheres e para a ampliação da participação feminina nos mais diversos campos profissionais.

No que tange à conquista dos direitos das mulheres, é inegável os avanços e a sua contribuição para que novos desafios para a concretização da equidade de gênero sejam enfrentados e vencidos. Nesta perspectiva, é importante também discutir as implicações da entrada das mulheres nas atividades profissionais para a organização e distribuição do trabalho no âmbito doméstico. As mulheres conquistaram o direito de participar da esfera produtiva, rompendo fronteiras entre o que era considerado atividade feminina e atividade masculina e gerando a necessidade de repensar a distribuição das tarefas domésticas a partir dessa nova realidade.

Mas quem deveria se responsabilizar por essas atividades? O âmbito reprodutivo sempre foi essencial para a manutenção da vida e, dessa forma, deveria ser de responsabilidade de todos(as). Além dos membros de cada família, sejam eles homens ou mulheres, também o Estado, por meio de políticas públicas poderia assumir parte dessas obrigações, efetivando a democratização do acesso à educação infantil, com possibilidade de educação em tempo integral; possibilitando maior acesso à saúde e ampliando espaços de cultura e lazer para pessoas idosas; implementando políticas de acesso e de desenvolvimentos de tecnologias e espaços coletivos que visem reduzir/facilitar o trabalho doméstico; efetivar uma melhor distribuição de renda, possibilitando que as camadas populares possam ter acesso a bens e serviços. Todas essas alternativas, não acabariam com as atividades do âmbito doméstico, nem seria esse o objetivo, mas poderiam facilitar a sua execução, como é o caso, por exemplo da máquina de lavar e secar que gerou uma redução considerável de tempo e esforço em relação ao que se despendia com o tanque de lavar roupa. Ainda assim, haveria a necessidade de partilhar e dividir o que não pode, não deve ou não se deseja que seja terceirizado ou delegado a outrem.

Diante dessa problemática, este artigo apresenta uma discussão sobre a divisão do trabalho doméstico em residências de famílias de mulheres trabalhadoras. Para isso, foi realizada uma pesquisa quantitativa entre as quinhentas e sessentas trabalhadoras do Instituto Federal de Santa Catarina (IF-SC), por meio de um questionário eletrônico, respondido por cento e vinte mulheres trabalhadoras do Instituto Federal de Santa Catarina, ou seja, por aproximadamente $21 \%$ da totalidade de mulheres (560 trabalhadoras). Os resultados obtidos na investigação demonstram que mesmo que essas mulheres tenham ocupado lugar no mercado de trabalho, no ambiente doméstico são elas que permanecem assumindo a maior parte das tarefas domésticas, sendo os homens vistos ainda como colaboradores, mesmo quando essas mulheres contribuem com a maior parcela da renda familiar.

\begin{tabular}{llll}
\hline №: 23-24 Ano: 13 jul/ago/set/out/nov/dez 2011 28 & $\mathbf{2 8}$ Cadernos de Gênero e Tecnologia
\end{tabular} 


\section{FAMÍLIA: AINDA UM ESPAÇO PATRIARCAL?}

O patriarcalismo é um dos sistemas que pode estruturar uma sociedade e é caracterizado pela supremacia masculina - uma suposta autoridade do homem é imposta sobre a família, buscando principalmente a subordinação da mulher ao homem.

Castells (1999) afirma que esse sistema permeia toda a organização da sociedade: produção, consumo, política, legislação e cultura. No entanto, ressalta que se vivencia um momento de crise desse modelo familiar, observado por meio dos seguintes aspectos:

- enfraquecimento das estruturas de dominação provocada pelos movimentos das mulheres;

- crises matrimoniais;

- fatores demográficos, como a diferença da taxa de mortalidade entre os sexos e o envelhecimento da população;

- $\quad$ instabilidade familiar e a crescente autonomia das mulheres com relação ao seu comportamento produtivo.

Para o autor, isto não significa o fim da família, pois outras formas familiares estão sendo constituídas. Ele defende que o que poderá se extinguir, ao longo do tempo, é a família patriarcal baseada no modelo de dominação masculina.

Sobre a questão da dominação masculina, destaca-se Bourdieu (1995) que estuda as diferenças entre os sexos, ressaltando que a dominação masculina e a submissão feminina foram construções sociais que se naturalizaram. Faz essa reflexão a partir da observação dos habitantes de Cabília, transpondo-as para as demais sociedades. Embora esse processo de generalização de resultados seja um grande problema, pois há sempre particularidades a serem consideradas e que influenciam os resultados de uma pesquisa, não podemos desprezar as contribuições do autor para a análise a que nos propomos neste trabalho. Assim, embora consciente da necessidade de relativização e de cuidado com qualquer tipo de universalização, considera-se relevante a as contribuições de Bourdieu, pois muito do que ele percebeu em outras sociedades, pode ser observada na nossa, contribuindo para a compreensão das relações de dominação que imperam na sociedade brasileira.

Assim, é relevante considerar que, segundo o autor, a visão dominante da divisão sexual está expressa nos discursos, nos espaços, na organização do tempo, nas práticas das técnicas e dos rituais e principalmente nas técnicas do corpo, ou seja, no habitus e na hexis corporal, funcionando "como um sistema de categorias de percepção, de pensamento e de ação” (BOURDIEU, 1995, p. 137). É importante considerar ainda que, segundo o autor, a força simbólica da oposição entre os sexos, pois, "todo poder comporta uma dimensão simbólica: ele deve obter dos dominados uma forma de adesão que não repousa sobre a decisão deliberada de uma consciência esclarecida, mas sobre a submissão imediata e préreflexiva de corpos socializados." (BOURDIEU, 1995, p. 142). Essa relação de poder faz com que a dominação masculina pareça natural, resultado de um processo de inculcação coletivo trabalhado sobre os corpos: diferenças biológicas são transformadas em diferenças sociais, processo que tem grande influência dos processos educativos.

Bourdieu (1995) expressa ainda que, em relação às oposições entre os sexos, a revolução industrial reafirmou a oposição entre o exterior e o interior, pois, aos homens coube o universo da empresa, orientado para a produção e o lucro, e às mulheres o universo da casa, voltado para a reprodução biológica, social e simbólica do lar. A entrada das mulheres no mercado de trabalho teria provocado, segundo o autor, um deslocamento dessas fronteiras, sem conseguir, no entanto, anulá-las. Além disso, "a entrada das mulheres na vida profissional forneceu uma prova manifesta de que a atividade doméstica não é socialmente reconhecida

№: 23-24 Ano: 13 jul/ago/set/out/nov/dez 2011 
como um verdadeiro trabalho; na verdade, negada ou denegada por sua própria evidência, a atividade doméstica continuou a se impor às mulheres por acréscimo" (BOURDIEU, 1995, p.170).

Bourdieu (1995, p.173) afirma ainda que a libertação das mulheres acontecerá quando elas subverterem as estruturas fundamentais do campo de produção e circulação dos bens simbólicos, pois esse lhes dá uma liberdade aparente para obter uma "submissão solícita e sua participação ativa num sistema de exploração e de dominação do qual elas são as primeiras vítimas".

Outra contribuição importante nesse debate é da historiadora Joan Scott. Para a autora (1995), gênero é um elemento constitutivo de relações sociais baseadas nas diferenças percebidas entre os sexos e uma forma primária de dar significado às relações de poder. Como elemento constitutivo das relações sociais, o gênero se manifesta nos símbolos culturalmente disponíveis; nos conceitos normativos que expressam as interpretações dos significados dos símbolos, tentando limitar e conter suas possibilidades metafóricas; na representação binária do gênero, como elemento de concepção política e suas referências às instituições e à organização social; e no aspecto do gênero como identidade subjetiva.

A autora esclarece, ainda, que o gênero é um campo primário no interior do qual, ou por meio do qual, o poder é articulado. Ele não é o único campo, mas se apresenta como uma forma persistente e recorrente de possibilitar a significação do poder no ocidente, nas tradições judaico-cristãs e islâmicas. Segundo a autora, o gênero fornece um meio de decodificação do significado e de compreensão das complexas conexões entre as várias formas de interação humana.

A partir dessas considerações iniciais, avaliamos que a compreensão das resistências masculinas em assumir o trabalho doméstico e a aceitação por grande parte das mulheres da responsabilidade sobre as atividades no âmbito doméstico está associada a relações de poder assimétricas estabelecidas entre homens e mulheres e a existência de uma hierarquização entre atividades masculinas e femininas. No entanto, a compreensão desse processo e, particularmente, a compreensão das formas de reprodução/alteração da tradicional divisão sexual do trabalho, dependem de uma análise da realidade concreta.

\section{O TRABALHO DOMÉSTICO}

Hirata e Kergoat (2007) tratam da divisão sexual do trabalho a partir de duas acepções. A primeira, denominada de sociográfica, estuda a distribuição desigual de homens e mulheres no mercado de trabalho e a divisão do trabalho doméstico entre os sexos. E, a segunda, derivada da anterior, é a que possibilita ir além da constatação das desigualdades na divisão sexual do trabalho, pois mostra que estas são sistemáticas, permitindo assim, articular essa descrição com uma reflexão sobre os processos utilizados pela sociedade para hierarquizar as atividades e criar um sistema de gênero. Para as autoras, o conceito de divisão sexual do trabalho está apoiado em dois princípios:

1) da separação: existem trabalhos de homens e trabalhos de mulheres; 2) hierárquico: o trabalho do homem vale mais que o trabalho da mulher. Devemos observar que essa divisão não é imutável, pois o que é considerado como trabalho masculino em uma sociedade, pode ser aceito como feminino em outra sociedade. Embora haja uma certa flexibilidade nessa divisão, é importante considerar que na maioria das sociedades capitalistas, seja por processos de segregação horizontal ou vertical, o trabalho masculino parece ter um valor maior do que o trabalho feminino.

№: 23-24 Ano: 13 jul/ago/set/out/nov/dez 2011 
Sobre as relações entre a esfera doméstica e a esfera profissional, Hirata e Kergoat (2007) apresentam quatro diferentes modelos de papéis sexuados:

- tradicional - o homem é o provedor e a mulher responsável por todo o trabalho doméstico;

- conciliação - a mulher concilia o trabalho doméstico com o trabalho profissional;

- delegação - o trabalho doméstico é terceirizado e realizado por alguém contratado para tal.

- $\quad$ parceria - baseado na igualdade de estatutos sociais entre os sexos, em que a mulher e o homem, como parceiros, dividem as tarefas domésticas.

Vale destacar que tais modelos se reproduzem por meio de processos de socialização de homens e mulheres. No modelo tradicional, provavelmente as meninas serão educadas para as atividades da esfera doméstica e os meninos para o trabalho tido como produtivo. Eles podem ocorrer concomitantemente: o modelo de delegação pode envolver o modelo tradicional - contratante delega e contratada continua assumindo sozinha as tarefas de sua residência.

Os modelos tradicional, de conciliação e de delegação parecem não alterar as relações de poder entre homens e mulheres e o sexo de quem executa as tarefas domésticas que permanecem sendo desenvolvidas por mulheres. Por outro lado, o modelo de parceria parece representar alterações significativas nessas relações, pois se existe partilha, solidariedade e cooperação na execução das atividades domésticas, provavelmente haverá uma possível valorização das atividades, redução da sobrecarga de trabalho (particularmente no modelo de conciliação), o que contribuirá para uma melhor qualidade de vida das mulheres com possibilidade de tempo para descanso, lazer ou aprimoramento pessoal e profissional feminino, repercutindo positivamente sobre a vida de todos(as).

\section{A PESQUISA SOBRE GÊNERO E TRABALHO DOMÉSTICO}

Com o objetivo de compreender como se dá a divisão de tarefas entre os sexos no ambiente doméstico das mulheres trabalhadoras, organizou-se uma pesquisa que tinha como universo as mulheres casadas ou em união estável e que trabalham no Instituto Federal de Santa Catarina (IF-SC).

Esse universo foi considerado interessante para a investigação por diversos fatores. Conforme pode ser observado na Tabela 1, há uma predominância masculina entre os trabalhadores (40\% de mulheres e $60 \%$ de homens). É importante observar, no entanto, que, embora não constituam uma maioria numericamente, as mulheres têm posição de destaque na Instituição, ocupando vários cargos de chefia: a reitoria, três pró-reitorias (das cinco existentes), várias diretorias e direções dos campi.

Esse contexto é bastante diferenciado da maioria das Instituições de Ensino da Rede Federal no Brasil, pois, nas Universidades Federais, de um total de 55, têm-se apenas 8 reitoras[4], e, nos Institutos Federais, são 5 reitoras[5], para um total de 37 instituições, o que demonstra que, no IF-SC, há uma situação política bastante positiva para as mulheres. 


\begin{tabular}{|c|c|c|c|c|c|c|c|}
\hline \multirow[t]{2}{*}{ impus } & \multicolumn{3}{|c|}{ Docertes } & \multicolumn{3}{|c|}{ Téaicos-uiministratimos } & \multirow{2}{*}{$\begin{array}{l}\text { Totslpa } \\
\text { compas }\end{array}$} \\
\hline & Mrosculino & Feminino & Tonl & Mrosculino & Fmirino & Tatsl & \\
\hline $\begin{array}{l}\text { inarargí } \\
\text { iaradar }\end{array}$ & $\frac{21}{1}$ & $\frac{19}{0}$ & $\begin{array}{c}40 \\
1\end{array}$ & $\frac{19}{0}$ & $\frac{12}{0}$ & $\begin{array}{c}31 \\
0\end{array}$ & $\begin{array}{c}71 \\
1\end{array}$ \\
\hline imointas & 0 & 1 & 1 & 0 & 0 & 0 & 1 \\
\hline $\begin{array}{l}\text { Trapecó } \\
\text { 'ortinerte }\end{array}$ & $\frac{25}{9}$ & $\frac{8}{30}$ & $\begin{array}{l}33 \\
39\end{array}$ & $\frac{14}{10}$ & $\frac{15}{22}$ & $\begin{array}{l}29 \\
32\end{array}$ & $\begin{array}{l}62 \\
71\end{array}$ \\
\hline ricímin & 1 & 0 & 1 & 0 & 0 & 0 & 1 \\
\hline Iarimópolis & 200 & 96 & 296 & 106 & 74 & 180 & 476 \\
\hline ว̆agpar & $\underline{1}$ & $\underline{0}$ & 1 & $\underline{0}$ & $\underline{0}$ & 0 & 1 \\
\hline tají & 1 & $\underline{0}$ & 1 & 0 & 0 & 0 & 1 \\
\hline angni do Syl & 27 & 20 & 47 & 12 & 23 & 35 & 82 \\
\hline oinville & $\underline{2}$ & 21 & 50 & 14 & 19 & 33 & 83 \\
\hline ages & $\underline{0}$ & $\underline{0}$ & 0 & $\underline{0}$ & $\underline{1}$ & 1 & 1 \\
\hline hog & $\overline{1}$ & $\overline{1}$ & 2 & $\overline{0}$ & $\overline{0}$ & 0 & 2 \\
\hline Tho José & 67 & 20 & 87 & 48 & 41 & 9 & 176 \\
\hline 5o Kigueldo Oeste & $\underline{I}$ & $\underline{0}$ & 1 & $\underline{0}$ & $\underline{0}$ & 0 & 1 \\
\hline Earker̂́ & 0 & $\overline{0}$ & 0 & $=$ & 1 & 1 & 1 \\
\hline beitorix & 129 & 62 & 191 & 92 & 74 & 166 & 357 \\
\hline / IFF0 25219 & 0 & 0 & 0 & & 0 & 0 & 0 \\
\hline atslmorulino & $\underline{513}$ & - & 513 & $\underline{315}$ & - & 315 & 828 \\
\hline atslFeminino & $\cdot$ & 278 & 278 & - & 282 & 282 & 560 \\
\hline [ otal & 513 & 278 & 791 & 315 & 282 & 597 & 1388 \\
\hline
\end{tabular}

Tabela 1. Distribuição dos(as) servidores(as) do IF-SC por campus e por sexo.

Fonte: Diretoria de Gestão de Pessoas do IFSC. (12/02/2010)

A partir dessa constatação - relevância do IF-SC para um processo investigatório sobre relações de gênero - houve uma motivação para conhecer a divisão sexual do trabalho no ambiente doméstico das mulheres que trabalham nesse Instituto, analisando como se dá a organização e divisão do trabalho nos ambientes domésticos dessas trabalhadoras. Algumas questões nortearão a nossa investigação: Elas assumem todo o trabalho? Dividem com seus companheiros? Que modelo é assumido por elas?

Esse trabalho adotou a pesquisa do tipo quantitativa, empregando como instrumento de coleta de dados um questionário, aplicado on-line, por meio da ferramenta Google ${ }^{\mathrm{TM}}$ Docs.

O universo da pesquisa foi o das 560 mulheres trabalhadoras do IF-SC, distribuídas entre vários campi no estado catarinense, conforme pode ser observado na tabela 1.

O questionário foi enviado por correio eletrônico às mulheres da Instituição, com auxílio do Setor de Marketing. A coleta de dados foi realizada entre os dias 19 e 26 de fevereiro de 2010 e, dentre as respostas que recebemos, a análise restringiu-se às respondentes casadas ou em união estável. A partir desse critério, dentre as 142 respostas recebidas, apenas 120 foram utilizadas. É importante esclarecer que, além das perguntas objetivas, o questionário dispunha de um espaço para comentários, que poderia ser utilizado espontaneamente. Das 120 respondentes, 37 fizeram observações que também serão objeto de análise neste trabalho.

\section{RESULTADOS E DISCUSSÕES}

Em relação ao perfil das entrevistadas, 53 são professoras e 67 ocupam funções técnico-administrativas. Quanto à formação acadêmica, elas são formadas em diversas áreas, abrangendo ciências agrárias, biológicas, da saúde, exatas e da terra, humanas, sociais 
aplicadas, engenharias e a lingüística, letras e artes. As idades das respondentes distribuemse da seguinte maneira: a) de 21 a 30 anos: $20 \%$ das respondentes; b) de 31 a 40 anos: 40,8 $\%$; c) de 41 a 50 anos: $32,5 \%$; d) mais de 50 anos: $6,7 \%$.

O nível de escolaridade das entrevistadas pode ser observado nos dados da tabela 2 , onde pode ser observado que a formação mínima é o ensino médio completo, que possuem

\begin{tabular}{|c|c|c|c|c|c|c|}
\hline \multirow[b]{3}{*}{ T arefa domés tica } & \multicolumn{6}{|c|}{ Sexo de quem realina } \\
\hline & \multicolumn{2}{|c|}{ femirino } & \multicolumn{2}{|c|}{ masculino } & \multicolumn{2}{|c|}{$\operatorname{anb} 0 s$} \\
\hline & $\begin{array}{l}\text { Húmero de } \\
\text { respostas }\end{array}$ & $\%$ & $\begin{array}{l}\text { Húmero de } \\
\text { respostas }\end{array}$ & $\%$ & $\begin{array}{l}\text { Húmero de } \\
\text { respostas }\end{array}$ & $\%$ \\
\hline farer compras & 28 & 23,3 & 9 & 7,5 & 83 & 692 \\
\hline guand ar oompras & 54 & 45,0 & 1 & 0,8 & 65 & 542 \\
\hline preparar a conida & 66 & 55,0 & 7 & 5,8 & 47 & 302 \\
\hline lavar a louça & 45 & 37,5 & 4 & 3,3 & 71 & 592 \\
\hline secare guardar a louça & 41 & 34,2 & 7 & 5,8 & 72 & 600 \\
\hline limpar a casa & 79 & 65,8 & 1 & 0,8 & 40 & 33,3 \\
\hline lingar banheiro & 98 & 81,7 & 3 & 2,5 & 19 & 15,8 \\
\hline lavar a youpa & 98 & 81,7 & 1 & 0,8 & 21 & 175 \\
\hline passar a roupa & 95 & 79,2 & 1 & 0,8 & 24 & 20,0 \\
\hline guardar a voupa & 90 & 75,0 & 1 & 0,8 & 29 & 24,2 \\
\hline
\end{tabular}

apenas $5 \%$ das mulheres.

Tabela 2. Nível de escolaridade das mulheres pesquisadas

Escolaridade

Nível médio completo

Graduação incompleta

Graduação completa

Mestrado incompleto

Mestrado completo

Doutorado incompleto

Doutorado completo

Total

Fonte: Pesquisa de campo.

Sobre a renda familiar das respondentes, pode-se observar que $10,8 \%$ têm renda entre $\mathrm{R} \$ 1.001,00$ e $\mathrm{R} \$ 3.000,00[6]$; 35\% têm renda entre $\mathrm{R} \$ 3.001,00$ e $\mathrm{R} \$ 5.000,00$; $19,2 \%$ estão na faixa de $\mathrm{R} \$ 5.001,00$ a $\mathrm{R} \$ 7.000,00 ; 17,5 \%$ têm renda entre $\mathrm{R} \$ 7.001,00$ a $\mathrm{R} \$ 9.000,00$; e para $17,5 \%$ a renda familiar é superior a $\mathrm{R} \$ 9.000,00$. Dessa maneira, observa-se que $45,8 \%$ das entrevistadas têm renda familiar inferior a $\mathrm{R} \$ 5.000,00$, e para $54,2 \%$ a renda é superior a esse valor.

Em relação à participação do salário das entrevistadas na renda familiar, apenas uma respondente afirmou contribuir com menos de $10 \%$ da renda familiar; 12 responderam que contribuem com valor entre $11 \%$ e $30 \%$; 44 afirmaram que a contribuição é de $31 \%$ a $50 \%$; outras 44 afirmaram que seus salários contribuem de $51 \%$ a $70 \%$ na renda familiar; 14 responderam que contribuem com valores entre $71 \%$ a $90 \%$; e 5 contribuem com mais de $90 \%$ na renda familiar. Considerando o modelo tradicional do homem provedor, como aquele que sustenta a família, pode-se identificar, aqui, mulheres que assumem esse papel, uma vez que a maioria delas contribui com mais de $50 \%$ da renda familiar. Destaca-se que a maioria das mulheres respondentes (107 delas) respondem por parcela significativo do orçamento familiar, pois contribuem com mais de $30 \%$ da renda familiar.

Foi indagado às pesquisadas sobre quem realiza o trabalho doméstico em suas 
residências. As respostas indicaram que é sempre a mulher que está à frente dessas atividades, embora contando, em muitos casos, com a "colaboração" do companheiro e de filhos(as). Pode-se constatar que 70 delas (aproximadamente $58 \%$ das respondentes) contratam alguém para fazer as atividades domésticas: 20 pesquisadas contratam uma empregada doméstica e 50 contam com uma diarista para a realização das atividades domésticas.

Para as mulheres que contam com a ajuda de uma profissional (diarista ou empregada doméstica) também foi perguntado quem gerencia o trabalho doméstico, e, novamente, a mulher aparece como a gestora desse trabalho, sendo que apenas 6 trabalhadoras declararam dividir essa tarefa com seus companheiros.

Uma das pesquisadas respondeu que "homens, quando participam das atividades domésticas, dizem 'que estão ajudando' e nunca que têm a mesma parcela de responsabilidade. No período em que estamos vivendo, é horrível pensar e agir dessa forma." (Professora, 41 a 50 anos, com contribuição de mais de $90 \%$ na renda familiar)

Para as pesquisadas foi indagado ainda sobre quem realiza determinadas atividades domésticas. Os resultados podem ser verificados na tabela 3. É importante ressaltar que os resultados demonstram que há algum compartilhamento dessas atividades, mas ainda é a mulher a responsável por elas. O percentual de homens que assumem sozinhos as tarefas domésticas específicas é muito pequeno. Eles ainda são vistos e por isso se vêem, em muitos casos, como colaboradores, pois, como assinalou uma das pesquisadas:

A divisão de tarefas entre os casais, ainda é um grande tabu. Na minha casa nós tentamos conciliar tudo, mesmo que às vezes algumas discussões ocorram por causa dessa divisão, por exemplo: se algo foi perdido a culpa é da mulher, se algo não foi feito a obrigação é da mulher. Os esposos esquecem que além da casa ainda temos que cuidar deles, dos filhos, de nós e da nossa vida profissional. (Pedagoga, 31 a 40 anos, com contribuição na renda familiar de 71 a 90\%).

Pelos resultados da pesquisa, pode-se observar que tarefas como lavar, passar e guardar a roupa, bem como limpar a casa e limpar banheiro são tarefas realizadas, em grande medida, pelas mulheres e as tarefas como fazer e guardas as compras, lavar, secar e guardar a louça são feitas por ambos. Fazer as compras é a tarefa com maior índice de realização pelos homens, mas com um índice de participação muito pequeno, pois apenas $7,5 \%$ deles assumem sozinhos essa responsabilidade.

Tabela 3. Distribuição das tarefas domésticas por sexo Fonte: Pesquisa de campo.

As respondentes também foram questionadas sobre a proporção do trabalho doméstico assumido por elas, e os resultados apontam novamente que as mulheres são as responsáveis pela maior parcela do trabalho doméstico, sendo que apenas uma respondeu ser responsável por menos da metade do trabalho doméstico. As demais (119) respondem ser responsáveis por mais de $60 \%$ das tarefas, sendo que 13 delas realizavam o trabalho sozinhas. É importante ressaltar que dessas 13 mulheres que realizam o trabalho sozinhas, 6 contribuem com mais de $50 \%$ da renda familiar, e uma delas é responsável por mais de $90 \%$ dos rendimentos da família.

Sobre a avaliação que as mulheres têm em relação à divisão do trabalho doméstico que vivenciam, pode-se observar que apenas $18 \%$ das mulheres se declararam insatisfeitas[7], enquanto que $52 \%$ parcialmente satisfeitas e $30 \%$ satisfeitas. Destas últimas, que

\begin{tabular}{lllll}
\hline №: 23-24 Ano: $13 \quad$ jul/ago/set/out/nov/dez 2011 & $\mathbf{3 4}$ & Cadernos de Gênero e Tecnologia
\end{tabular}


representam 36 mulheres, 21 contribuem com mais de 50\% da renda familiar e, destas, apenas 6 dividem o trabalho equitativamente com seus companheiros; as demais declararam assumir $60 \%$ ou mais das tarefas domésticas.

Cabe mencionar que uma das pesquisadas declarou sentir prazer em realizar atividades domésticas:

Vale salientar que, mesmo me sentindo sobrecarregada nos afazeres da casa em comparação ao meu companheiro, tento não viver estressada com esta condição. Se der para esperar até o dia da faxineira vir, espero. Faço somente aquilo de extrema relevância para a manutenção da casa como lavar a roupa, fazer comida e lavar a louça. E, por incrível que pareça - muitas feministas gostariam de me matar - muitas dessas vezes, faço as atividades domésticas com prazer e me sinto bastante recompensada com um simples elogio (da comida, por exemplo). (Professora, 31 a 40 anos, com contribuição de 31 a 50\% na renda familiar).

As trabalhadoras também foram questionadas sobre o processo de negociação acerca da divisão das tarefas domésticas e eventuais conflitos nessa negociação. Aproximadamente metade das respondentes $(46,9 \%)$ declarou que existe uma negociação familiar para a distribuição das atividades. Destaca-se o fato de que 16,8\% declararam que esse processo é conflituoso, em grande medida por existir resistência do marido ou do companheiro em assumir tais tarefas.

Em relação ao tempo dedicado às tarefas domésticas, 32,5\% afirmaram ser inferior a 10 horas semanais, $48,3 \%$ utilizam mais de 10 horas e menos de 20 horas semanais, $15,8 \%$ se dedicam mais de 20 e menos de 40 horas semanais, e apenas 3,3\% trabalham mais de 40 horas em atividades da casa. Já, em relação ao tempo de lazer, $62 \%$ das pesquisadas afirmaram que o trabalho doméstico reduz o tempo de lazer.

\section{CONSIDERAÇÕES FINAIS}

A análise da divisão sexual do trabalho doméstico, baseada em Hirata e Kergoat (2007), demonstra que as trabalhadoras pesquisadas ocupam espaços no mundo do trabalho, contribuem na renda familiar, em muitos casos com a maior parcela, sendo algumas as provedoras do lar, mas, mesmo assim, mantêm, em seus ambientes domésticos, a estrutura dominante do modelo tradicional de família, em que a mulher é responsável pelo trabalho doméstico, fazendo a conciliação com o trabalho profissional.

Observa-se que a divisão equitativa das tarefas domésticas, entre homens e mulheres, ainda não é uma realidade entre as pesquisadas, pois a maioria declarou ser responsável pela maior parcela das atividades domésticas. Isto demonstra que o modelo de parceria ainda está longe de ser alcançado pelas mulheres trabalhadoras do IF-SC.

A delegação do trabalho doméstico é utilizada por uma parcela considerável das pesquisadas, seja de maneira parcial, quando contrata uma diarista, ou de forma mais completa, quando conta com a colaboração de uma empregada doméstica, mas, em ambos os casos, cabe a essas mulheres a gestão do trabalho dessas profissionais.

Mesmo que estejamos observando uma ruptura com o modelo patriarcal, conforme defende Castells (1999), verificamos, pelos resultados da pesquisa, que as tarefas domésticas

No: 23-24 Ano: 13 jul/ago/set/out/nov/dez 2011 
ainda são, em sua maioria, assumidas pelas mulheres, mesmo para aquelas que contribuem com a maior parcela da renda familiar. Isto demonstra que ainda há muito a ser feito. Conforme observado por uma das entrevistadas: "O maior problema das mulheres da nossa faixa etária é que buscamos a independência trabalhando fora, e nos esquecemos de brigar para que os maridos também trabalhem dentro de casa." (Técnica em eletrotécnica, 41 a 50 anos, contribuição de 51 a $70 \%$ na renda familiar).

A pesquisa mostra que o trabalho doméstico foi "naturalizado" e está incorporado no modo de vida das mulheres, e estas têm uma grande parcela de responsabilidade pela reprodução do modelo instituído, pois há indícios de que as mulheres estejam lutando mais no ambiente de trabalho produtivo e, não raro resignando-se com a situação doméstica assimétrica na divisão sexual do trabalho.

\section{NOTAS}

[1] Doutoranda do Programa de Pós-graduação em Tecnologia da Universidade tecnológica Federal do Paraná. Professora do Instituto Federal de Santa Catarina - cmartins@ifsc.edu.br.

[2] Doutora em Política Científica e Tecnológica. Professora do Programa de Pós-graduação em Tecnologia e do Departamento Acadêmico de Matemática da Universidade tecnológica Federal do Paraná - nancist@ terra.com.br.

[3] Doutora em Antropologia Social. Professora do Programa de Pós-graduação em Tecnologia da Universidade Tecnológica Federal do Paraná - mariliagdecarvalho@gmail.com

[4] Fonte: Associação Nacional dos Dirigentes da Instituições Federais de Ensino Superior (ANDIFES). Disponível em: http://www.andifes.org.br. Acesso em 01 de fevereiro de 2010.

[5] Fonte: D.O.U. de 8 de janeiro de 2009. Disponível em: http://portal.mec.gov.br/arquivos/pdf/port_reitores.pdf . acesso em 01 de fevereiro de 2010.

[6] O valor do salário mínimo vigente no país no momento da pesquisa era de $\mathrm{R} \$ 510,00$.

[7] Para a análise dessa respostas foram considerados somente a percepção de satisfação de cada pesquisada. A satisfação aqui se refere unicamente a uma avaliação positiva ou negativa da forma como são divididas as tarefas em suas residências.

\section{REFERÊNCIAS}

BORDIEU, Pierre. A dominação masculina. In: Educação e Realidade, 1995. p.133-184.

CASTELLS, Manuel. O fim do patriarcalismo: movimentos sociais, família e sexualidade na era da informação. In: CASTELLS, Manuel. O poder da identidade. São Paulo: Paz e Terra, 1999. p. 169-285.

HIRATA, Helena e KERGOAT, Daniéle. Novas configurações da divisão sexual do trabalho. In: Cadernos de Pesquisa, v. 37 n. 132, p. 595-609, set/dez 2007.

NICHOLSON, Linda. Interpretando gênero. In: Revista Estudos Feministas, 2000. p. 9-41.

SCOTT, Joan. Gênero: uma categoria útil de análise histórica. In: Educação e Realidade. Vol. 20, no.2, Porto Alegre:

UFRGS, 1995. p.71-99. 